\title{
Review Article \\ Merkel Cell Carcinoma: Chemotherapy and Emerging New Therapeutic Options
}

\author{
Laura Desch and Rainer Kunstfeld \\ Universitätsklinik für Dermatologie, AKH, Medizinische Universität Wien, Währinger Gürtel 18-20, 1090 Wien, Austria \\ Correspondence should be addressed to Rainer Kunstfeld; rainer.kunstfeld@meduniwien.ac.at
}

Received 25 July 2012; Accepted 10 December 2012

Academic Editor: Boban M. Erovic

Copyright (C) 2013 L. Desch and R. Kunstfeld. This is an open access article distributed under the Creative Commons Attribution License, which permits unrestricted use, distribution, and reproduction in any medium, provided the original work is properly cited.

\begin{abstract}
Merkel cell carcinoma (MCC) is a rare neuroendocrine skin tumor that typically occurs in elderly, immunosuppressed patients. Infection with Merkel cell virus (MCV) and immunosuppression play an important role in the development of MCC. Different staging systems make it difficult to compare the existing clinical data. Furthermore, there predominantly exist single case reports and case series, but no randomized controlled trials. However, it is necessary to develop further therapy options because MCC tends to grow rapidly and metastasizes early. In the metastatic disease, therapeutic attempts were made with various chemotherapeutic combination regimens. Because of the high toxicity of these combinations, especially those established in SCLC, and regarding the unsatisfying results, the challenge is to balance the pros and cons of chemotherapy individually and carefully. Up to now, emerging new therapy options as molecular-targeted agents, for example, pazopanib, imatinib, or somatostatin analogues as well as immunologicals, for example, imiquimod and interferons, also showed less success concerning the disease-free response rates. According to the literature, neither chemotherapy nor molecular-targeted agents or immunotherapeutic strategies have shown promising effects in the therapy of the metastatic disease of MCC so far. There is a great demand for randomized controlled studies and a need for an MCC registry and multicenter clinical trials due to the tumors curiosity.
\end{abstract}

\section{Clinical Features}

Merkel cell carcinoma (MCC) of the skin, formerly called trabecular carcinoma, is a rare, highly malignant neuroendocrine tumor. Clinically only a presumptive diagnosis can be achieved. Clinical features that may serve as clues in the diagnosis of MCC are summarized in the acronym AEIOU: asymptomatic/lack of tenderness, expanding rapidly, immune suppression, older than age 50, and UV-exposed site on a person with fair skin [1]. The definitive diagnosis is made by histology and immunohistopathology depicting intermediate filaments and neuroendocrine markers [2]. The incidence of MCC has been rising in recent years [3, 4]. 5 years after diagnosis, overall survival was $40 \%$ and the ageadjusted and sex-adjusted survival was 54\% [5].

Infection with the Merkel cell virus (MCV) and immunosuppression are the key factors in the development of MCC. The relative risk for MCC is about 13-fold higher in HIV [6] and about 5-fold higher in solid organ transplantation recipients [7] than in the general population. On the one hand, these features might also explain the increasing incidence of MCC. On the other hand, they might be key factors for the successful treatment of MCC.

The stage of patients with MCC has prognostic impact and influences the therapy offered. Over the years, different staging systems of MCC have been applied making it difficult to compare clinical data. In 2010, the American Joint Committee on Cancer (AJCC) Staging system first included the staging for MCC [8]. Duprat et al. [9] summarized AJCC Staging system and five-year survival data from Lemos et al. [5] in a table. Clinicians and researchers should be cautious when comparing clinical studies which applied older systems and with those which applied the recent AJCC Staging system.

MCC mostly appears as a hemispherical, firm-elastic, and reddish-livid tumor with a smooth surface. It is typically 
located on sun exposed areas like head, neck, extremities, and upper body [10]. Because of its harmless appearance, this rare neuroendocrine tumor, first described by Toker in 1972 [11], is often misdiagnosed, for example, as a cyst [1]. Interestingly, the clinically suspected diagnosis has only been made correctly for one percent of the cases $[1,12]$. The MCC grows rapidly, is highly aggressive, and metastasizes early locoregionally as well as distantly $[1,13]$ illustrating the importance of comprehensive strategies to control disseminated diseases.

\section{Therapeutic Options}

The rareness of the disease and, possibly also the comorbidities have contributed to the lack of prospective clinical studies evaluating the efficacy of therapeutic options. Up to now, only one randomized clinical study was published [34]. All other publications refer uncontrolled data from case series or even retrospective case descriptions.

The only randomized controlled clinical study published in the field of MCC compared regional adjuvant radiotherapy with observation [34]. While adjuvant radiotherapy significantly reduced the probability of regional recurrence, it had no effect on the overall survival. The authors wrote that the introduction of sentinel node dissection decreased the recruitment rate for this study. Surgery is considered the mainstay of treatment for MCC [10]. However, there is no evidence basis for this treatment option. A prospective evaluation of sentinel node dissection in MCC was described only in 9 patients [35].

\section{Chemotherapeutic Options: Polychemotherapy and Monotherapeutic Options}

Basically MCC is assumed to be a chemosensitive tumor [12, $36,37]$ but to date no broadly accepted treatment algorithm exists. Supportively to primary excision, chemotherapy is used on MCC stages III (lymph node metastasis) and IV (distant metastases) after the AJCC Staging system. It may be applied either alone or in combination with radiotherapy. Furthermore, chemotherapeutics are used in locally advanced disease, as palliative measure or in case of recurrences [37].

The following data refers to retrospective case series or single case reports, except [14, 15] and (Table 1) [19], which are prospective case series. Several groups tried to treat MCC with chemotherapeutic regimens commonly used for small cell lung cancer (SCLC) because of histopathological and cytochemical similarities-besides both of them are considered as neuroendocrine tumors [16, 38-42]. These regimens combined carboplatin, cisplatin, and etoposide, cyclophosphamide with vincristine, doxorubicin, prednisone, bleomycin, or 5-fluorouracil (Table 1). They were reported to provide a good initial regression of the lesion, but recurrences occurred mainly within 4 to 15 months. All these patients had locoregional or distant metastases. These potential benefits should be weighed against the possible adverse reactions of these therapeutic attempts. Some of these rather old patients died from sepsis caused by chemotherapyinduced leukopenia [40], progressive renal failure [17], or impaired hepatic function [37].

In a retrospective analysis of a series of 251 patients from a single centre treated between 1970 and 2002 (Table 1) [24], the use of adjuvant chemotherapy was associated with decreased survival. 28 of 237 patients presenting with locally advanced disease or locoregional metastases received adjuvant chemotherapy and showed a 5-year disease-specific survival rate of $28 \%$ compared to $73 \%$ of 209 patients without receiving chemotherapy. Furthermore, 67 node-positive patients receiving chemotherapy were associated with a lower survival rate compared to not-receiving chemotherapy.

Beside polychemotherapy with burdensome toxicity, there are better tolerated monotherapeutic options like etoposide and anthracyclines [10, 25, 37]. Liposomal doxorubicin together with radiotherapy $(n=5)$ yielded rapid response, but showed less adverse reactions, for example, gastrointestinal disorders. Tumor proceeded within 1 to 3 months (Table 1) [25]. Orally administered etoposide achieved complete responses in 3 out of 4 patients (75\%) and two of them were comparatively long lasting (16 and 36 months) (Table 1) [26].

There are no randomized studies that compare different chemotherapy regimens. In 204 patients, the most common regimens used were cyclophosphamide, doxorubicin (or epirubicin), vincristine plus/or minus prednisone, and etoposide combined with cisplatin (or carboplatin). A relevant difference in the response rate could not be described (Table 1) [27].

Although high remission rates were reported after chemotherapy (up to $70-75 \%[25,37]$ ), but no such prolongation of survival [10]. Intensity of chemotherapeutic therapy and response rates did not correlate [37]. Main therapy still is wide excision of the tumor with or without node dissection, often in combination with radiotherapy. In comparison, chemotherapy has been used rarely [45].

Up to now, the literature does not provide adequate, sufficient data to support the use of chemotherapy.

\section{Molecular-Targeted Agents}

Davids et al. (Table 2) [28] treated a patient who suffered from metastatic pulmonary lesions with pazopanib, which is a small-molecule tyrosine kinase inhibitor acting against vascular-endothelial-growth-factor-receptors- (VEGFR-) 1, 2 , and 3 and against platelet-derived-growth-factor-receptor(PDGFR-) $\alpha$ and $\beta$. The rationale was that MCCs have been shown having upregulated VEGFR $[46,47]$ and PDGFR $[48,49]$. Pazopanib can be administered orally. It was well tolerated and provided partial response of the pulmonary lesions as well as complete response of the primary lesion, but disease recurred or rather progressed 4 months later. In this case, every other therapy that had been tried before (surgery, radiotherapy, etoposide and carboplatin, paclitaxel, tegafur, and 5-chloro-2,4-dihydroxypyridine and oxonic acid) also led to partial or complete response and lesions recurred 4-8 


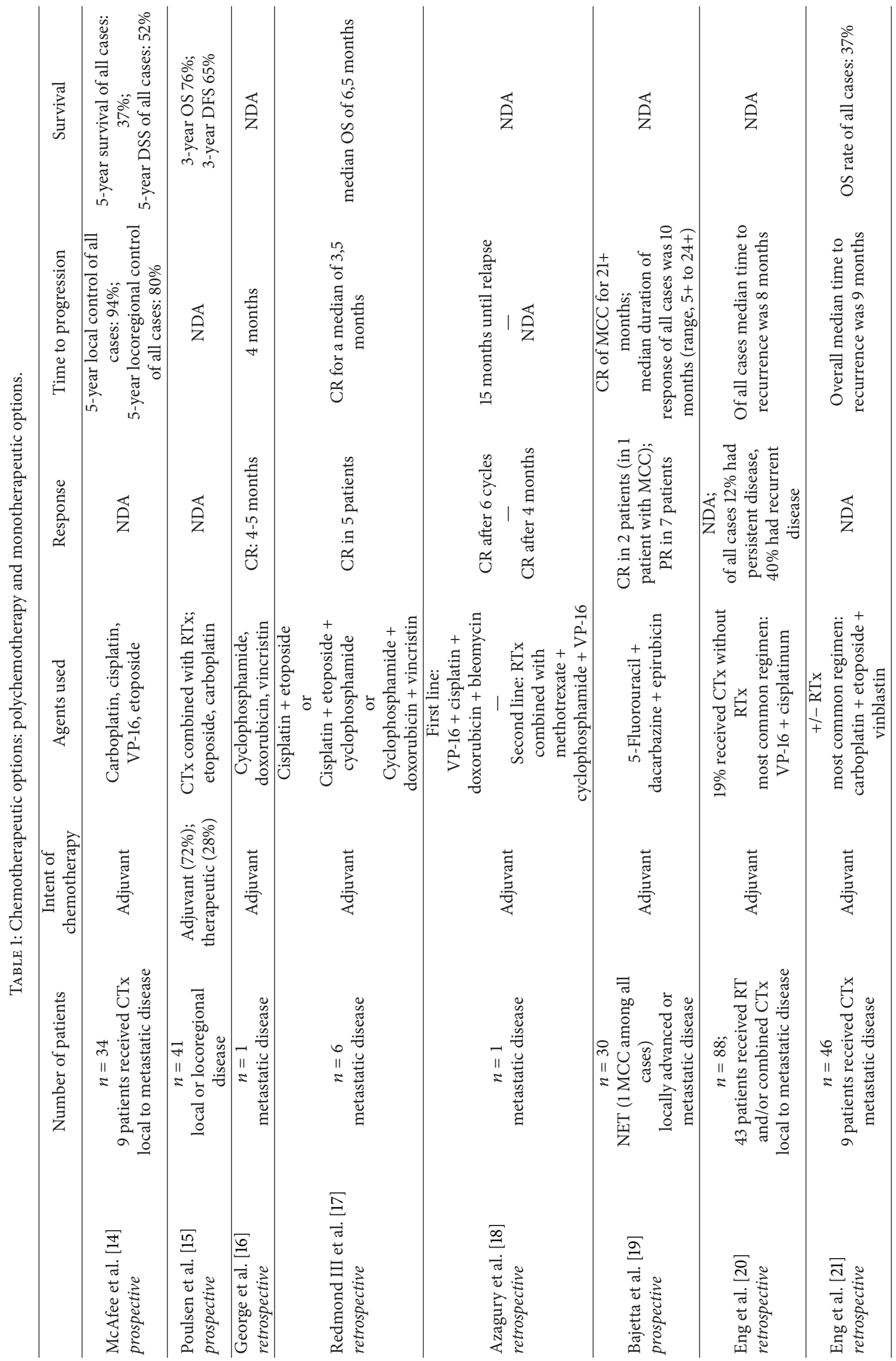




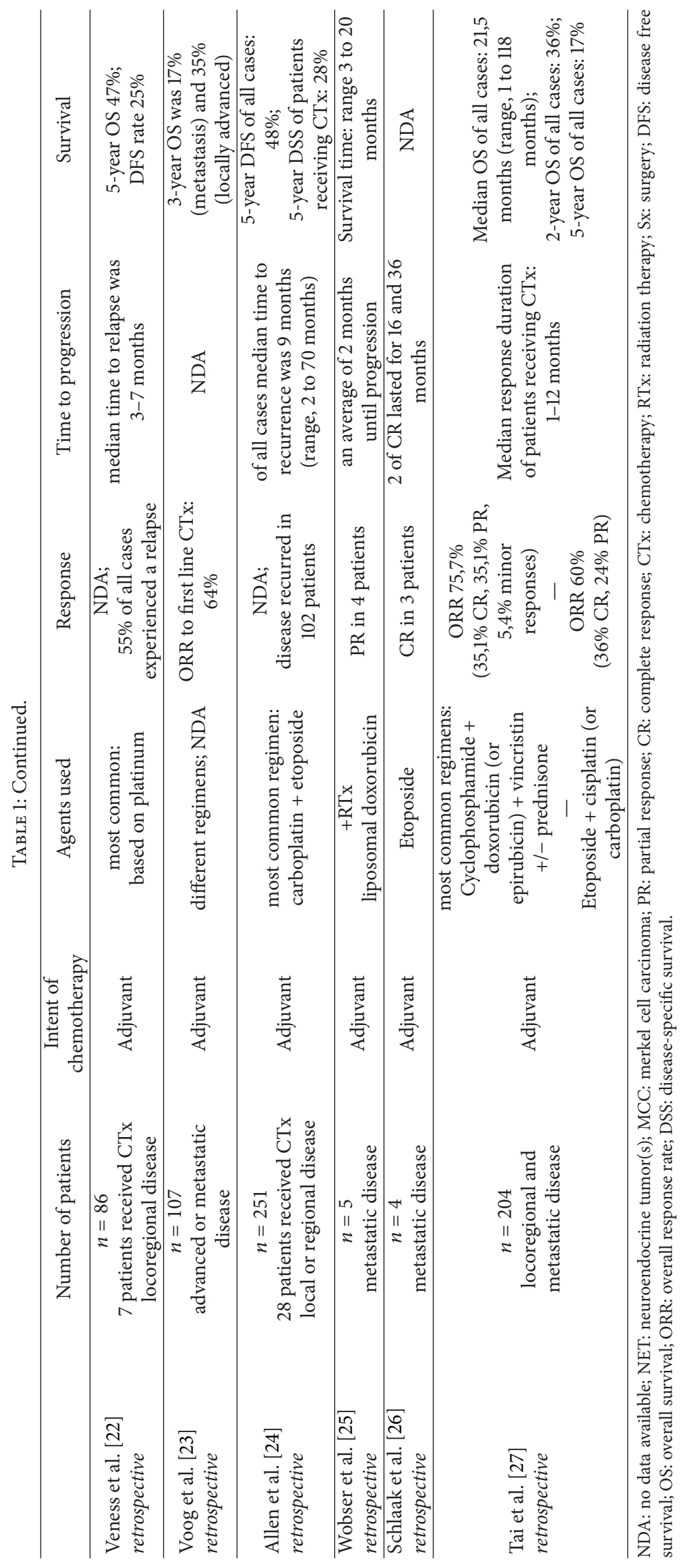




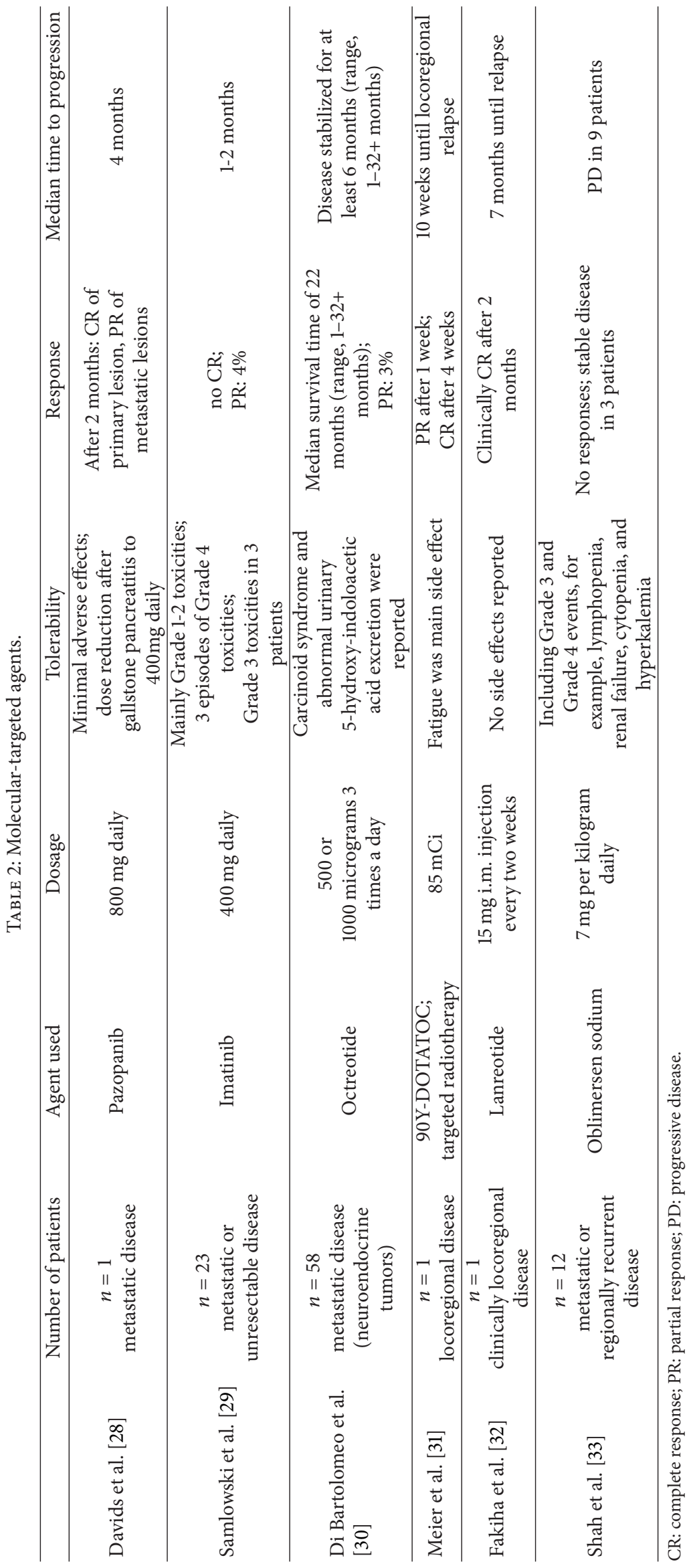


and once 24 months later. In this paper, the authors conclude that pazopanib appears to have a promising antitumor and antiangiogenic function and good oral bioavailability; as per them, this has been demonstrated in preclinical studies.

In this patient, single nucleotide polymorphism (SNP) in PDGFR- $\alpha$ gene was found, namely, 1432T $>$ C mutation in codon 478. The same mutation was shown in two other samples of MCCs that were examined by this group and in three other patients with MCC from another study [49]. It is not clear whether this mutation leads to an activation of PDGFR- $\alpha$ and consequently to a better response to tyrosine kinase inhibitors, for example, pazopanib or not.

Similarly well tolerated is another tyrosine kinase inhibitor called imatinib mesylate (Gleevec) (Table 2) [29]. KIT (CD117), a tyrosine kinase receptor which belongs to the same family of tyrosine kinase receptors like PDGFR- $\alpha$, is reported to be highly expressed (84-95\%) in MCCs [50-52]. Activating mutations of KIT were found in $88,2 \%(n=127)$ of gastrointestinal stromal tumors (GISTs) and showed a significantly higher partial response rate to imatinib for exon 11 KIT mutation (83.5\%) compared to exon 9 KIT mutation $(47.8 \%)$ or no found mutation $(0.0 \%)$ [53]. Because of the successful treatment of KIT expressing GISTs [53, 54] and because of the recent insight that KIT receptor activation through its ligand stem cell factor (SCF) stimulates growing of MCC cells in vitro [55], imatinib was assumed to be a promising therapeutic option for MCC. In fact, there were only few adverse events but imatinib appeared to provide insufficient effects on progression-free and overall survival. Just one out of 23 patients with KIT expressing MCCs responded partially and the progression happened rapidly after 1 or 2 months in most of the patients. Thus, the study was prematurely discontinued [29].

Kartha and Sundram [48] examined primary and metastatic MCCs $(n=32)$ to evaluate the expression and mutations of KIT and PDGFR in MCCs. KIT expression was found in 53\% of the cases. Coexpression of KIT and SCF was shown in $16 \%$ only, whereas coexpression of PDGFR$\alpha$ and its ligand PDGF-A was found in $81 \%$ of the cases. In this study, no activating mutations could be found (KIT exons $9,11,13$, and 17 and PDGFR- $\alpha$ exons 10,12 , and 18 were analyzed). Therefore, efficacy of imatinib is questionable, also considering results of Samlowski et al. [29].

Somatostatin receptors were also reported to be expressed in MCCs. Somatostatin analogue octreotide showed unfruitful results concerning tumor regression with a partial response rate of $3 \%(n=58)$ (Table 2) [30]. Radiopeptide therapy is used to treat neuroendocrine tumors by binding of edotreotide (DOTATOC, which contains the active peptide of somatostatin, namely, octreotid) to somatostatin receptors. In one case, the radiolabeled somatostatin analog $90 \mathrm{Y}-$ DOTATOC led to complete remissions after a few days, but relapse and progression occurred within weeks. It has to be pointed out that the tolerability was very good (Table 2) [31]. Lanreotide, a nonradiolabeled somatostatin analog, was intramuscularly administered in one patient every two weeks and showed a complete response of the lesion. Recurrences occurred within 7 months after the first injection (Table 2) [32].
Oblimersen sodium (Genasense), which inhibits the production of $\mathrm{Bcl}-2$ (which is a protein acting against apoptosis in cancer cells), was applied intravenously to 12 patients and showed no responses (Table 2) [33].

\section{Immunotherapeutic Strategies}

MCC is associated with immunosuppression $[1,4]$. Cases of spontaneous regressions of MCCs were reported that were deemed to be caused by the regained activity of the immune system $[56,57]$. MCCs that showed a high infiltration with CD8+ lymphocytes were attributed to a better prognosis (100\% MCC-specific survival, $n=26$ ) compared to MCCs with lower infiltration (60\% survival, $n=120$ ) [58].

Some patients developed MCC during treatment with tumor necrosis factor (TNF) alpha inhibitors, which usually promotes inflammatory response. Therefore, TNF-alpha inhibitors are assumed to increase the risk of occurring of $\operatorname{MCC}[59,60]$.

The detection of the Merkel cell polyomavirus (MCV) and its genetic material, found in MCC tumor cells of about $80 \%$ of the concerned patients, provided new opportunities and possibilities regarding therapy strategies [61, 62]. For instance, interferons ( $\alpha$ and $\beta$ ) have been suggested to be a possible therapeutic option [63]. However, there are only few reports on the use of immunomodulating substances in MCC. In two case reports, interferon- $\alpha$-2b caused severe asthenia and depression, leading to discontinuation of the therapy, considering that no tumor regression was observed. The tumors were positive for MCV [63]. Recently, it has been shown that viral T-antigens represent an important signal for MCV-infected MCC cells concerning survival and growth [64]. Consequently, the inhibition of T-antigens might be a therapeutic option.

Imiquimod, which induces immune response by binding to TLR7 (toll like receptor-7, located on the surface of immune cells, e.g., macrophages), was topically applied to $\operatorname{MCC}(n=1)$ and combined with radiotherapy. Complete response of the lesion lasted 7 months [65].

Another new therapeutic approach is based on cytokine inducted inflammatory response. To avoid systemic reactions, fusion proteins were developed consisting of antibodies and cytokines, which bind to their corresponding antigens located on the tumor cell surface [66]. In general, combined therapy of cytokine-based antibodies and regular chemotherapy seems to be well tolerated.

\section{Conclusions}

There is a considerable lack of prospective clinical studies and in particular randomized controlled studies that evaluated the therapeutic options for MCC. For the time being, nearly all conclusions are based on case series or even isolated cases and theoretic considerations, rather than evidencebased medicine.

With respect to chemotherapeutics or molecular-targeted agents, no convincing responses were reported; at best the responses lasted a few months or just several weeks. There 
were no controlled studies. Thus, the question arises whether there truly is a benefit of chemotherapy for MCC; if any, the benefit is unlikely to be relevant. Because of frequent comorbidities of the older patient collective, it is necessary to develop therapy modalities that are effective and more likely to be tolerated. The recent insight of an association of MCC to MCV infection and immunosuppression enables new therapeutic options, for example, the inhibition of viral $\mathrm{T}$-antigens, that requests further investigations. Currently, there is an ongoing phase II trial study with the purpose of placing the gene for interleukin-12 into MCC cells by intratumoral injection so that humans build up an immune defense and may kill tumor cells. Other promising options might be immune-response modifiers.

This emerging disease requires more clinical research. A first step might be the implementation of an MCC registry. More important, however, would be randomized controlled studies in this field, which are urgently needed. The often rapid deterioration of this cancer and the frequent comorbidities might require rather simple protocols. The rareness of the disease calls for the implementation of an MCC network to collect sufficient numbers of patients in an MCC registry and multicenter clinical trials.

\section{References}

[1] M. Heath, N. Jaimes, B. Lemos et al., "Clinical characteristics of Merkel cell carcinoma at diagnosis in 195 patients: the AEIOU features," Journal of the American Academy of Dermatology, vol. 58, no. 3, pp. 375-381, 2008.

[2] U. Meyer-Pannwitt, K. Kummerfeldt, P. Boubaris, and J. Caselitz, "Merkel cell tumor or neuroendocrine skin carcinoma," Langenbecks Archiv für Chirurgie, vol. 382, no. 6, pp. 349-358, 1997.

[3] D. Lyhne, J. Lock-Andersen, K. Dahlstrøm et al., "Rising incidence of Merkel cell carcinoma," Journal of Plastic Surgery and Hand Surgery, vol. 45, no. 6, pp. 274-280, 2011.

[4] M. Agelli, L. X. Clegg, J. C. Becker, and D. E. Rollison, "The etiology and epidemiology of merkel cell carcinoma," Current Problems in Cancer, vol. 34, no. 1, pp. 14-37, 2010.

[5] B. D. Lemos, B. E. Storer, J. G. Iyer et al., "Pathologic nodal evaluation improves prognostic accuracy in Merkel cell carcinoma: analysis of 5823 cases as the basis of the first consensus staging system," Journal of the American Academy of Dermatology, vol. 63, no. 5, pp. 751-761, 2010.

[6] E. A. Engels, M. Frisch, J. J. Goedert, R. J. Biggar, and R. W. Miller, "Merkel cell carcinoma and HIV infection," Lancet, vol. 359, no. 9305, pp. 497-498, 2002.

[7] E. Lanoy, D. Costagliola, and E. A. Engels, "Skin cancers associated with HIV infection and solid-organ transplantation among elderly adults," International Journal of Cancer, vol. 126, no. 7, pp. 1724-1731, 2010.

[8] American Joint Committee on Cancer, "Merkel cell carcinoma," in AJCC Cancer Staging Handbook, pp. 377-386, Springer, New York, NY, USA, 2010.

[9] J. P. Duprat, G. Landman, J. V. Salvajoli, and E. R. Brechtbühl, "A review of the epidemiology and treatment of Merkel cell carcinoma," Clinics, vol. 66, no. 10, pp. 1817-1823, 2011.

[10] J. C. Becker, "Merkel cell carcinoma," Annals of Oncology, vol. 21, supplement 7, pp. vii81-vii85, 2010.
[11] C. Toker, "Trabecular carcinoma of the skin," Archives of Dermatology, vol. 105, no. 1, pp. 107-110, 1972.

[12] L. Steinstraesser, M. Kueckelhaus, and V. Koljonen, "Recent update on tumour biology and treatment of merkel cell carcinoma," Handchirurgie Mikrochirurgie Plastische Chirurgie, vol. 43, no. 6, pp. 345-349, 2011 (German).

[13] V. Koljonen, "Merkel cell carcinoma," World Journal of Surgical Oncology, vol. 4, article 7, 2006.

[14] W. J. McAfee, C. G. Morris, C. M. Mendenhall, J. W. Werning, N. P. Mendenhall, and W. M. Mendenhall, "Merkel cell carcinoma: treatment and outcomes," Cancer, vol. 104, no. 8, pp. 1761-1764, 2005.

[15] M. Poulsen, D. Rischin, E. Walpole et al., "High-risk Merkel cell carcinoma of the skin treated with synchronous carboplatin/etoposide and radiation: a Trans-Tasman Radiation Oncology Group Study-TROG 96:07,' Journal of Clinical Oncology, vol. 21, no. 23, pp. 4371-4376, 2003.

[16] T. K. George, P. A. di Sant'agnese, and J. M. Bennett, "Chemotherapy for metastatic Merkel cell carcinoma," Cancer, vol. 56, no. 5, pp. 1034-1038, 1985.

[17] J. Redmond III, J. Perry, P. Sowray, S. J. Vukelja, and N. Dawson, "Chemotherapy of disseminated merkel-cell carcinoma," American Journal of Clinical Oncology, vol. 14, no. 4, pp. 305-307, 1991.

[18] M. Azagury, B. Chevallier, D. Atlan, Y. Graic, J. P. Dayot, and E. Thomine, "VP-16, cisplatin, doxorubicin, and bleomycin in metastatic Merkel cell carcinoma. Report of a case with longterm remission," American Journal of Clinical Oncology, vol. 16, no. 2, pp. 102-104, 1993.

[19] E. Bajetta, L. Rimassa, C. Carnaghi et al., "5-fluorouracil, dacarbazine, and epirubicin in the treatment of patients with neuroendocrine tumors," Cancer, vol. 83 , no. 2, pp. 372-378, 1998.

[20] T. Y. Eng, M. G. K. Boersma, C. D. Fuller, S. X. Cavanaugh, F. Valenzuela, and T. S. Herman, "Treatment of merkel cell carcinoma," American Journal of Clinical Oncology, vol. 27, no. 5, pp. 510-515, 2004.

[21] T. Y. Eng, M. Naguib, C. D. Fuller, W. E. Jones III, and T. S. Herman, "Treatment of recurrent merkel cell carcinoma: an analysis of 46 cases," American Journal of Clinical Oncology, vol. 27, no. 6, pp. 576-583, 2004.

[22] M. J. Veness, L. Perera, J. McCourt et al., "Merkel cell carcinoma: improved outcome with adjuvant radiotherapy," ANZ Journal of Surgery, vol. 75, no. 5, pp. 275-281, 2005.

[23] E. Voog, P. Biron, J. P. Martin, and J. Y. Blay, "Chemotherapy for patients with locally advanced or metastatic Merkel cell carcinoma," Cancer, vol. 85, no. 12, pp. 2589-2595, 1999.

[24] P. J. Allen, W. B. Bowne, D. P. Jaques, M. F. Brennan, K. Busam, and D. G. Coit, "Merkel cell carcinoma: prognosis and treatment of patients from a single institution," Journal of Clinical Oncology, vol. 23, no. 10, pp. 2300-2309, 2005.

[25] M. Wobser, N. Kürzinger, S. Ugurel, E. B. Bröcker, and J. C. Becker, "Therapy of metastasized Merkel cell carcinoma with liposomal doxorubicin in combination with radiotherapy," Journal der Deutschen Dermatologischen Gesellschaft, vol. 7, no. 6, pp. 521-525, 2009 (German).

[26] M. Schlaak, T. Podewski, W. Von Bartenwerffer et al., "Induction of durable responses by oral etoposide monochemotherapy in patients with metastatic Merkel cell carcinoma," European Journal of Dermatology, vol. 22, no. 2, pp. 187-191, 2012.

[27] P. T. H. Tai, E. Yu, E. Winquist et al., "Chemotherapy in neuroendocrine/Merkel cell carcinoma of the skin: case series and 
review of 204 cases," Journal of Clinical Oncology, vol. 18, no. 12, pp. 2493-2499, 2000.

[28] M. Davids, A. Charlton, S. S. Ng et al., "Response to a novel multitargeted tyrosine kinase inhibitor pazopanib in metastatic merkel cell carcinoma," Journal of Clinical Oncology, vol. 27, no. 26, pp. e97-e100, 2009, Erratum in: Journal of Clinical Oncology, vol. 28 , no. 18, p. 3098, 2010.

[29] W. E. Samlowski, J. Moon, R. J. Tuthill et al., "A phase II trial of imatinib mesylate in merkel cell carcinoma (neuroendocrine carcinoma of the skin): a Southwest Oncology Group study (S0331)," American Journal of Clinical Oncology, vol. 33, no. 5, pp. 495-499, 2010.

[30] M. di Bartolomeo, E. Bajetta, R. Buzzoni et al., "Clinical efficacy of octreotide in the treatment of metastatic neuroendocrine tumors. A study by the Italian Trials in Medical Oncology Group," Cancer, vol. 77, no. 2, pp. 402-408, 1996.

[31] G. Meier, C. Waldherr, R. Herrmann, H. Maecke, J. MuellerBrand, and M. Pless, "Successful targeted radiotherapy with 90Y-DOTATOC in a patient with Merkel cell carcinoma: a case report," Oncology, vol. 66, no. 2, pp. 160-163, 2004.

[32] M. Fakiha, P. Letertre, J. P. Vuillez, and J. Lebeau, "Remission of Merkel cell tumor after somatostatin analog treatment," Journal of Cancer Research and Therapeutics, vol. 6, no. 3, pp. 382-384, 2010.

[33] M. H. Shah, K. A. Varker, M. Collamore et al., "G3139 (Genasense) in patients with advanced merkel cell carcinoma," American Journal of Clinical Oncology, vol. 32, no. 2, pp. 174-179, 2009.

[34] T. Jouary, C. Leyral, B. Dreno et al., "Adjuvant prophylactic regional radiotherapy versus observation in stage I Merkel cell carcinoma: a multicentric prospective randomized study," Annals of Oncology, vol. 23, no. 4, pp. 1074-1080, 2012.

[35] E. Migliano, C. Monarca, M. Tedesco, M. I. Rizzo, and S. Bucher, "Merkel cell carcinoma and sentinel lymph node dissection: nine cases report," Il Giornale di Chirurgia, vol. 29, no. 1-2, pp. 28-32, 2008 (Italian).

[36] D. Schrama, S. Ugurel, and J. C. Becker, "Merkel cell carcinoma: recent insights and new treatment options," Current Opinion in Oncology, vol. 24, no. 2, pp. 141-149, 2012.

[37] J. Becker, C. Mauch, R. D. Kortmann et al., "Short German guidelines: Merkel cell carcinoma," Journal der Deutschen Dermatologischen Gesellschaft, vol. 6, supplement 1, pp. S15-S16, 2008 (German).

[38] S. Pilotti, F. Rilke, and L. Lombardi, "Neuroendocrine (Merkel cell) carcinoma of the skin," American Journal of Surgical Pathology, vol. 6, no. 3, pp. 243-254, 1982.

[39] R. K. Sibley, J. Rosai, E. Foucar, L. P. Dehner, and G. Bosl, "Neuroendocrine (Merkel cell) carcinoma of the skin. A histologic and ultrastructural study of two cases," American Journal of Surgical Pathology, vol. 4, no. 3, pp. 211-221, 1980.

[40] J. B. Taxy, D. S. Ettinger, and M. D. Wharam, "Primary small cell carcinoma of the skin," Cancer, vol. 46, no. 10, pp. 2308-2311, 1980.

[41] M. H. Kroll and C. Toker, "Trabecular carcinoma of the skin: further clinicopathologic and morphologic study," Archives of Pathology and Laboratory Medicine, vol. 106, no. 8, pp. 404-408, 1982.

[42] S. V. Pollack and J. B. Goslen, "Small-cell neuroepithelial tumor of skin. A Merkel-cell neoplasm?” Journal of Dermatologic Surgery and Oncology, vol. 8, no. 2, pp. 116-122, 1982.
[43] P. J. Allen, Z. F. Zhang, and D. G. Coit, "Surgical management of Merkel cell carcinoma," Annals of Surgery, vol. 229, no. 1, pp. 97-105, 1999.

[44] E. R. Kokoska, M. S. Kokoska, B. T. Collins, D. R. Stapleton, and T. P. Wade, "Early aggressive treatment for merkel cell carcinoma improves outcome," American Journal of Surgery, vol. 174, no. 6, pp. 688-693, 1997.

[45] S. Henness and P. Vereecken, "Management of Merkel tumours: an evidence-based review," Current Opinion in Oncology, vol. 20, no. 3, pp. 280-286, 2008.

[46] M. T. Fernández-Figueras, L. Puig, E. Musulén et al., "Expression profiles associated with aggressive behavior in Merkel cell carcinoma," Modern Pathology, vol. 20, no. 1, pp. 90-101, 2007.

[47] H. Kukko, V. Koljonen, P. Lassus, E. Tukiainen, C. Haglund, and T. Böhling, "Expression of vascular endothelial growth factor receptor-2 in Merkel cell carcinoma," Anticancer Research, vol. 27, no. 4C, pp. 2587-2589, 2007.

[48] R. V. Kartha and U. N. Sundram, "Silent mutations in KIT and PDGFRA and coexpression of receptors with SCF and PDGFA in Merkel cell carcinoma: implications for tyrosine kinase-based tumorigenesis," Modern Pathology, vol. 21, no. 2, pp. 96-104, 2008.

[49] B. L. Swick, L. Ravdel, J. E. Fitzpatrick, and W. A. Robinson, "Platelet-derived growth factor receptor alpha mutational status and immunohistochemical expression in Merkel cell carcinoma: implications for treatment with imatinib mesylate," Journal of Cutaneous Pathology, vol. 35, no. 2, pp. 197-202, 2008.

[50] M. Feinmesser, M. Halpern, E. Kaganovsky et al., "c-kit expression in primary and metastatic merkel cell carcinoma," American Journal of Dermatopathology, vol. 26, no. 6, pp. 458462, 2004.

[51] L. D. Su, D. R. Fullen, L. Lowe, P. Uherova, B. Schnitzer, and R. Valdez, "CD117 (KIT receptor) expression in Merkel cell carcinoma," American Journal of Dermatopathology, vol. 24, no. 4, pp. 289-293, 2002.

[52] S. Strong, K. Shalders, R. Carr, and D. R. J. Snead, "KIT receptor (CD117) expression in Merkel cell carcinoma," British Journal of Dermatology, vol. 150, no. 2, pp. 384-385, 2004.

[53] M. C. Heinrich, C. L. Corless, G. D. Demetri et al., "Kinase mutations and imatinib response in patients with metastatic gastrointestinal stromal tumor," Journal of Clinical Oncology, vol. 21, no. 23, pp. 4342-4349, 2003.

[54] G. D. Demetri, M. von Mehren, C. D. Blanke et al., "Efficacy and safety of imatinib mesylate in advanced gastrointestinal stromal tumors," The New England Journal of Medicine, vol. 347, no. 7, pp. 472-480, 2002.

[55] K. Krasagakis, I. Fragiadaki, M. Metaxari et al., "KIT receptor activation by autocrine and paracrine stem cell factor stimulates growth of merkel cell carcinoma in vitro," Journal of Cellular Physiology, vol. 226, no. 4, pp. 1099-1109, 2011.

[56] A. G. Richetta, M. Mancini, A. Torroni et al., "Total spontaneous regression of advanced merkel cell carcinoma after biopsy: review and a new case," Dermatologic Surgery, vol. 34, no. 6, pp. 815-822, 2008.

[57] J. C. Wooff, J. R. Trites, N. M. G. Walsh, and M. J. Bullock, "Complete spontaneous regression of metastatic merkel cell carcinoma: a case report and review of the literature," American Journal of Dermatopathology, vol. 32, no. 6, pp. 614-617, 2010.

[58] K. G. Paulson, J. G. Iyer, A. R. Tegeder et al., "Transcriptomewide studies of merkel cell carcinoma and validation of intratumoral CD8+ lymphocyte invasion as an independent predictor 
of survival," Journal of Clinical Oncology, vol. 29, no. 12, pp. 1539-1546, 2011.

[59] S. M. Krishna and C. N. Kim, "Merkel cell carcinoma in a patient treated with adalimumab: case report," Cutis, vol. 87, no. 2, pp. 81-84, 2011.

[60] S. P. Linn-Rasker, G. A. van Albada-Kuipers, S. V. Dubois, K. Janssen, and P. G. Zweers, "Merkel cell carcinoma during treatment with TNF-alpha inhibitors: coincidence or warning?" Nederlands Tijdschrift voor Geneeskunde, vol. 156, no. 22, article A4464, 2012 (Dutch).

[61] D. E. Rollison, A. R. Giuliano, and J. C. Becker, "New virus associated with Merkel cell carcinoma development," Journal of the National Comprehensive Cancer Network, vol. 8, no. 8, pp. 874-880, 2010.

[62] H. Feng, M. Shuda, Y. Chang, and P. S. Moore, "Clonal integration of a polyomavirus in human Merkel cell carcinoma," Science, vol. 319, no. 5866, pp. 1096-1100, 2008.

[63] C. Biver-Dalle, T. Nguyen, A. Touzé et al., "Use of interferonalpha in two patients with Merkel cell carcinoma positive for Merkel cell polyomavirus," Acta Oncologica, vol. 50, no. 3, pp. 479-480, 2011.

[64] R. Houben, M. Shuda, R. Weinkam et al., "Merkel cell polyomavirus-infected Merkel cell carcinoma cells require expression of viral T antigens," Journal of Virology, vol. 84, no. 14, pp. 7064-7072, 2010.

[65] M. Balducci, B. De Bari, S. Manfrida, G. R. D’Agostino, and V. Valentini, "Treatment of Merkel cell carcinoma with radiotherapy and imiquimod (Aldara): a case report," Tumori, vol. 96, no. 3, pp. 508-511, 2010.

[66] D. Schrama, R. A. Reisfeld, and J. C. Becker, "Antibody targeted drugs as cancer therapeutics," Nature Reviews Drug Discovery, vol. 5, no. 2, pp. 147-159, 2006. 


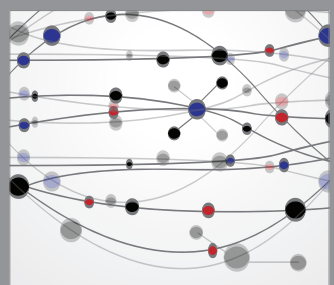

The Scientific World Journal
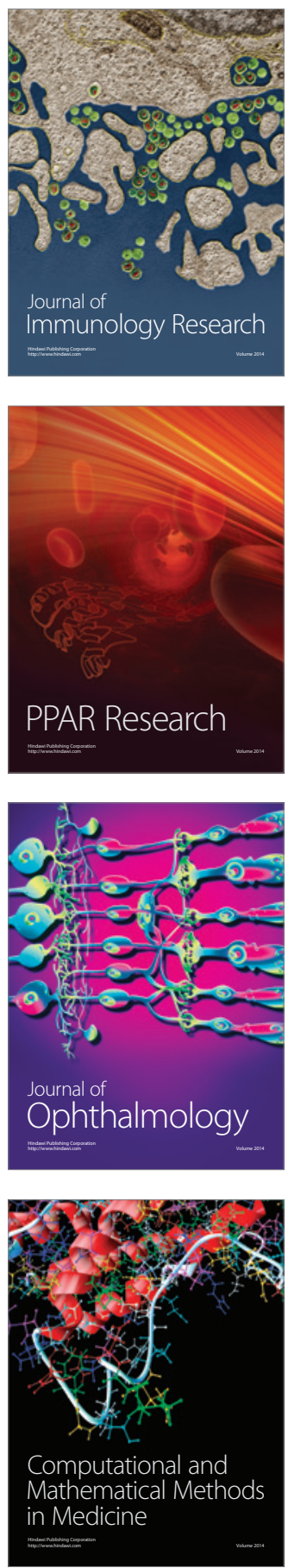

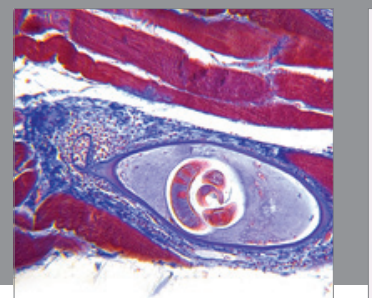

Gastroenterology

Research and Practice
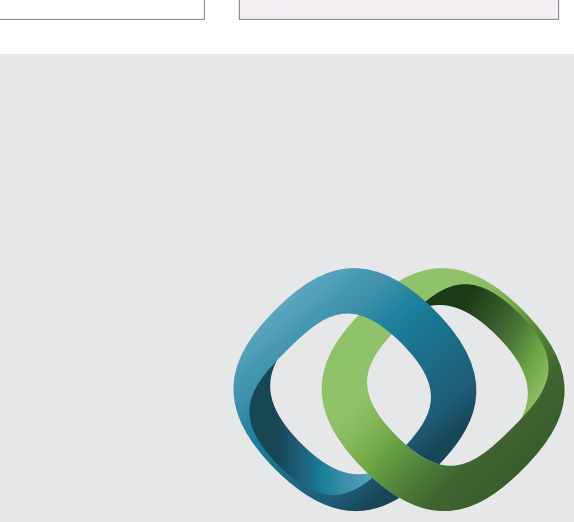

\section{Hindawi}

Submit your manuscripts at

http://www.hindawi.com
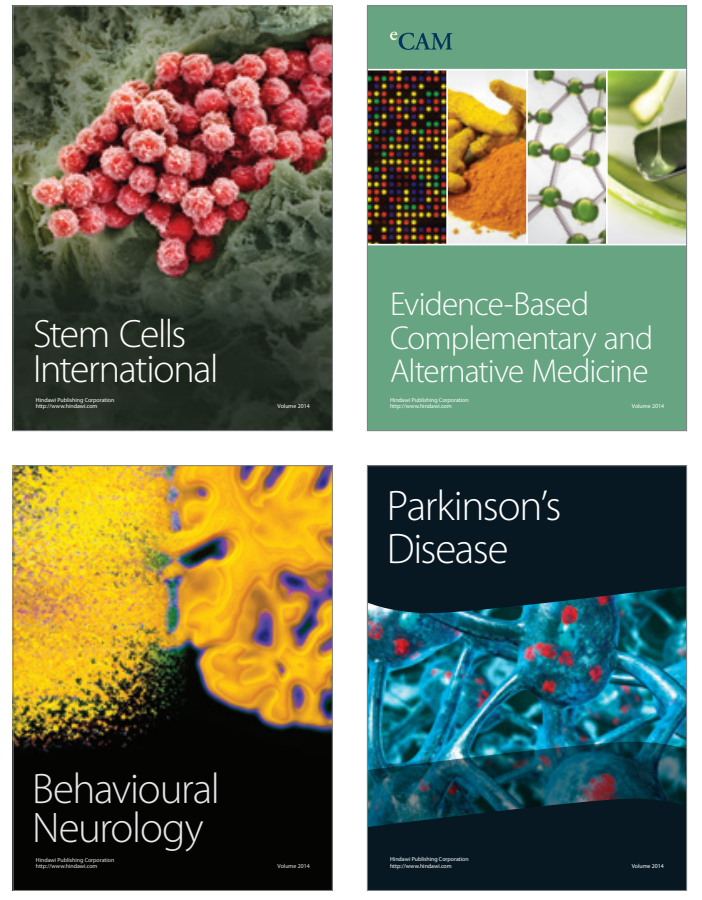
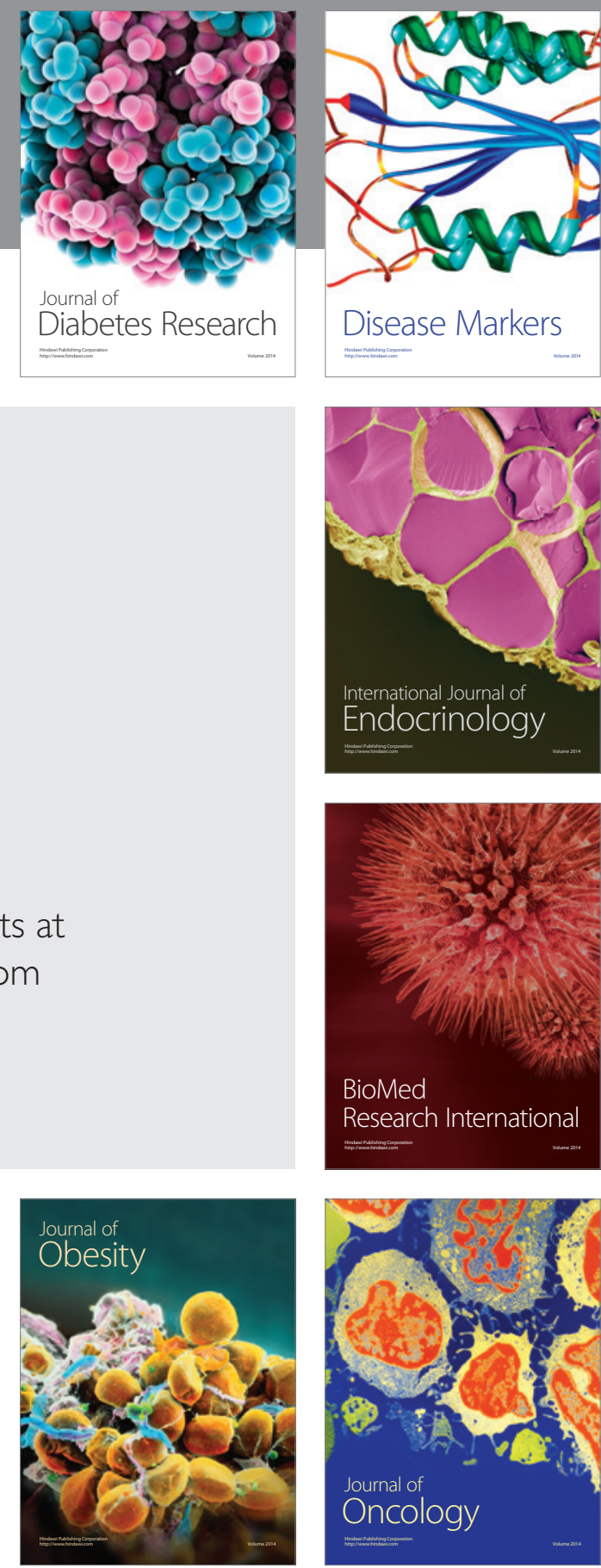

Disease Markers
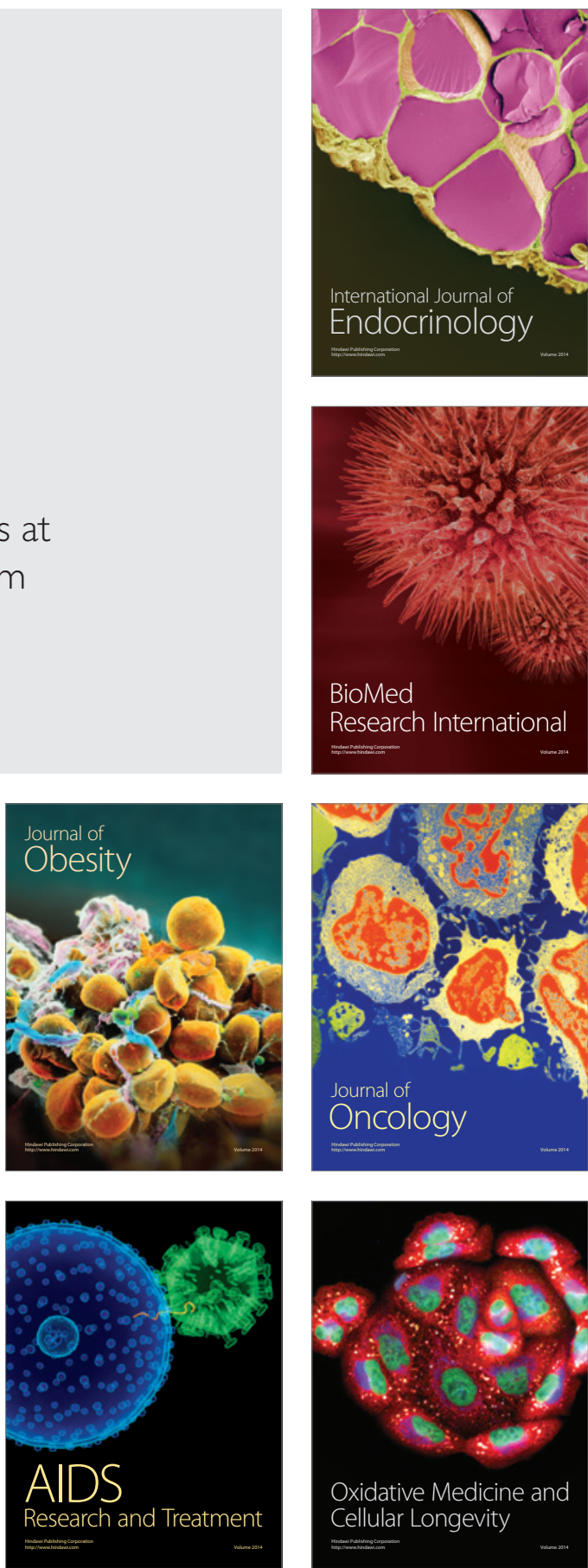